\title{
A importância da cooperação internacional na formação superior de angolanos
}

\author{
Ermelinda Liberato*
}

\begin{abstract}
Resumo
A cooperação internacional tem assumido, nos últimos anos, um protagonismo e importância nos diferentes sectores, sobretudo no que toca a formação e qualificação de recursos humanos. Para Angola, um país que tem atravessado diferentes constrangimentos essa importância acentua-se, pois, a formação de recursos humanos tem sido possível sobretudo com a realização de diferentes acordos de cooperação celebrados com diferentes países do mundo, dentre os quais se destacam Portugal e Brasil.

Palavras-chave: Ensino Superior; Cooperação Internacional; Angola.
\end{abstract}

\section{The importance of international cooperation for Angolans higher education}

\begin{abstract}
International cooperation has taken in recent years, a protagonism and importance in various sectors, especially regarding the training and qualification of human resources. For Angola, a country that has gone through various constraints this importance is emphasized, considering that the training of human resources has been possible mainly with the implementation of various cooperation agreements with different countries, which stand out Portugal and Brazil.

Keywords: Higher Education; International Cooperation; Angola.
\end{abstract}

\section{Introdução}

A educação superior em Angola tem passado por diversos constrangimentos que têm condicionado a sua evolução positiva bem como a sua afirmação no cenário internacional e até regional o que tem levado, ao longo dos anos, à saída de estudantes angolanos para o exterior, em busca de melhores oportunidades de formação. Essa deslocação realça a importância da cooperação em todo esse processo pois, é no âmbito dos acordos estabelecidos que são decididos os países de destino, bem como as condições a que os estudantes ficam sujeitos.

Neste processo, Portugal e Brasil, assumem um papel de destaque. As ligações históricas e culturais bem como a partilha do mesmo idioma, fortaleceram as relações de amizade e de cooperação com estes países, e funcionaram como fatores decisivos na escolha do destino para a formação superior. Por outro lado, as dinâmicas que as sociedades atualmente estão sujeitas realçam ainda mais a importância do estabelecimento desse tipo de acordos, tendo como fim único a melhoria da qualificação de recursos humanos, para que os mesmos possam ser envolvidos no processo de desenvolvimento dos respetivos países.

Assim, começamos por abordar o papel que a cooperação internacional tem assumido ao longo dos anos, com destaque para os anos mais recentes. De seguida, analisamos, de forma breve, os motivos

\footnotetext{
*Endereço Eletrônico: ermelinda.liberato@gmail.com
}

que têm levado à saída de jovens angolanos para o exterior tendo como objetivo a realização a formação superior, uma prática que vem do tempo colonial e que se estendeu durante o período socialista (1975-1991), intensificando-se nos anos seguintes, como o reinício da guerra civil. Para terminar, focamos a relação de proximidade entre Angola, Portugal e o Brasil, dois importantes destinos dos estudantes angolanos, bem como dois importantes países no que toca aos acordos de cooperação para o ensino superior.

\section{A importância da cooperação na formação superior de angolanos}

A cooperação define-se como um processo social através do qual os seus intervenientes procuram realizar objetivos comuns. Quanto à cooperação entre estados, de acordo com Fernandes; Martins e Rodrigues:

A cooperação afirma-se como um dever dos estados, uns perante os outros, dentro dos princípios de subsidiariedade contidos na carta das Nações Unidas. Quer na relação estado a estado, quer de forma multilateral, cooperar significa evitar que os países sofram uma dependência total do exterior, vivam uma marginalização face ao mundo de alto padrão de rendimento e caiam numa pobreza crescente (FERNANDES; MARTINS; RODRIGUES, 2005, p. 15). 
Na celebração de protocolos de cooperação está assim implícita a "criação de mecanismos e o estabelecimento de laços de solidariedade" (AFONSO, 1995, p. 13), bem como uma conjugação de esforços tendo em vista o mesmo fim.

A cooperação entre Estados (cooperação bilateral) pode abranger diversas áreas (económica, cultural, educativa, saúde, etc.). O conceito assume especial importância na década de 1970 ao ser utilizado para caraterizar a necessidade de desenvolvimento dos estados recém-independentes. $\mathrm{Na}$ altura, a cooperação era entendida como a prestação da ajuda aos países menos desenvolvidos ajuda dos países do norte aos países do sul (cooperação norte-sul) - vista durante muitos anos como "um ato unilateral de caridade" (PNUD, 2005, p. 7). As alterações políticas e económicas ocorridas um pouco por todo o mundo conduziram a uma evolução deste conceito de cooperação reorientandoo para a:

Necessidade de transferência de tecnologia, a participação dos técnicos dos países beneficiários na conceção e execução dos projetos, a responsabilização das populações na utilização dos benefícios colhidos na cooperação, a formação constante de técnicos que possam dar continuidade às ações iniciadas em cada programa ou projeto (FERNANDES; MARTINS; RODRIGUES, 2005, p. 15).

Por outro lado, ganha cada vez mais relevância a cooperação entre os países do sul (cooperação sul-sul), que envolve soluções e tecnologias desenvolvidas pelos próprios países do sul (onde se inscreve a cooperação Angola-Brasil).

A Cimeira do Milénio (2000) deu início a um novo cenário no processo de cooperação, ao dar origem a um compromisso político assumido pelos Estados na defesa dos princípios de liberdade e igualdade, respeito pelo ambiente e partilha de responsabilidades. Os Objetivos de Desenvolvimento do Milénio (ODM) passaram assim a constituir o quadro de referência de cooperação entre os países uma vez que é com base nestes objetivos gerais que cada país doador estabelece as metas específicas da sua política de cooperação. No que toca à cooperação na área da educação, esta assenta, sobretudo, numa troca de apoios mediante protocolos estabelecidos entre países, tendo como fim a reciprocidade na partilha de recursos humanos, mas igualmente a consolidação das relações de amizade e de alianças políticas. Orientados pelos ODM, os protocolos de cooperação na área da educação passaram a assentar, sobretudo, no ensino primário, de modo a se atingir a meta estabelecida para 2015: alcançar o ensino primário universal. Embora o destaque seja atribuído ao ensino primário, no "quadro do acordo estratégico da União Europeia (UE) para África, adotado em Outubro de 2005 , e que promove a realização dos ODM, é reconhecida a importância do desenvolvimento do ensino superior e da sua internacionalização (CARVALHO, 2010, p. 43). Deste modo, a cooperação internacional, no âmbito do ensino superior, assume particular importância nos programas de cooperação com os países do continente africano, sendo Angola um dos países beneficiários. Essa cooperação passa, não só pelo acolhimento de estudantes africanos nas instituições de ensino superior dos países desenvolvidos e pela atribuição de bolsas de estudo, mas, sobretudo, pela criação de redes universitárias, pela partilha de recursos e conhecimentos, pela investigação em parceria, assim como pela integração das universidades africanas no contexto internacional. É neste contexto que Portugal e o Brasil assumem papéis específicos na cooperação com Angola, na área da educação superior, recebendo anualmente, um número significativo de estudantes angolanos nos seus estabelecimentos de ensino.

\section{O período colonial}

Até 1963, data de início de funcionamento dos Estudos Gerais Universitários de Angola, a formação superior de angolanos e daqueles que viviam em Angola, tinha que ser realizada fora deste território, nomeadamente, em Portugal. Esse privilégio, de acesso ao ensino superior e de viajar até à metrópole, apresentava-se acessível a um número muito pequeno de beneficiados que constituíam, na altura, uma pequena elite. Os encargos financeiros relacionados com a deslocação e permanência na metrópole constituíam já de si uma forte condicionante uma vez que, os custos inerentes a esse processo ficavam ao encargo da família.

$\mathrm{O}$ atraso na criação do subsistema de ensino superior, apesar das exigências da população e de muitas promessas políticas feitas ao longo dos anos, deveu-se não somente ao atraso que a educação registava como, igualmente, ao fato de Portugal se mostrar receoso com a "insurgência que daí poderia resultar, desenvolvendo uma política de manter na maior ignorância os povos africanos, não fossem eles despertar para ambições inconvenientes" (LARA, 1999, p. 35). Assim, quando os Estudos 
Gerais são instituídos e entram em funcionamento, perspetivava-se uma melhoria do nível da educação da população de Angola, em geral, dando possibilidade de continuidade dos estudos a parte da população que, de outra maneira não conseguiria.
A criação dos Estudos Gerais em Angola, frequentados maioritariamente por brancos, não fez, no entanto, diminuir a saída de estudantes deste território ultramarino para a metrópole.

Quadro 1. $\mathrm{N}^{\mathrm{o}}$ de estudantes universitários inscritos nas universidades portuguesas e $\mathrm{n}^{\mathrm{o}}$ de estudantes angolanos inscritos nos Estudos Gerais

\begin{tabular}{|l|r|r|}
\hline Anos & $\begin{array}{l}\text { Estudantes Angolanos em } \\
\text { Universidades Portuguesas }\end{array}$ & $\begin{array}{l}\text { Estudantes Angolanos matriculados } \\
\text { nos Estudos Gerais em Angola }\end{array}$ \\
\hline $1961 / 62$ & 855 & 286 \\
\hline $1962 / 63$ & 839 & 418 \\
\hline $1963 / 64$ & 951 & 477 \\
\hline $1964 / 65$ & 1035 & 607 \\
\hline $1965 / 66$ & 1065 & 827 \\
\hline $1966 / 67$ & 1200 & 1074 \\
\hline $1967 / 68$ & 1172 & 1570 \\
\hline $1968 / 69$ & 1305 & 2088 \\
\hline $1969 / 70$ & 1297 & 2435 \\
\hline $1970 / 71$ & 1345 & \\
\hline $1971 / 72$ & 1337 & \\
\hline $1972 / 73$ & Elaboração da autora & \\
\hline \multicolumn{2}{|r|}{ Fonte: baseado em Anuário Estatístico do Ultrarar e Anuário Estatístico da Província de Angola } \\
\end{tabular}

Figura $1 . \mathrm{N}^{\mathrm{o}}$ de estudantes universitários inscritos nas universidades portuguesas e $\mathrm{n}^{\mathrm{o}}$ de estudantes angolanos inscritos nos Estudos Gerais

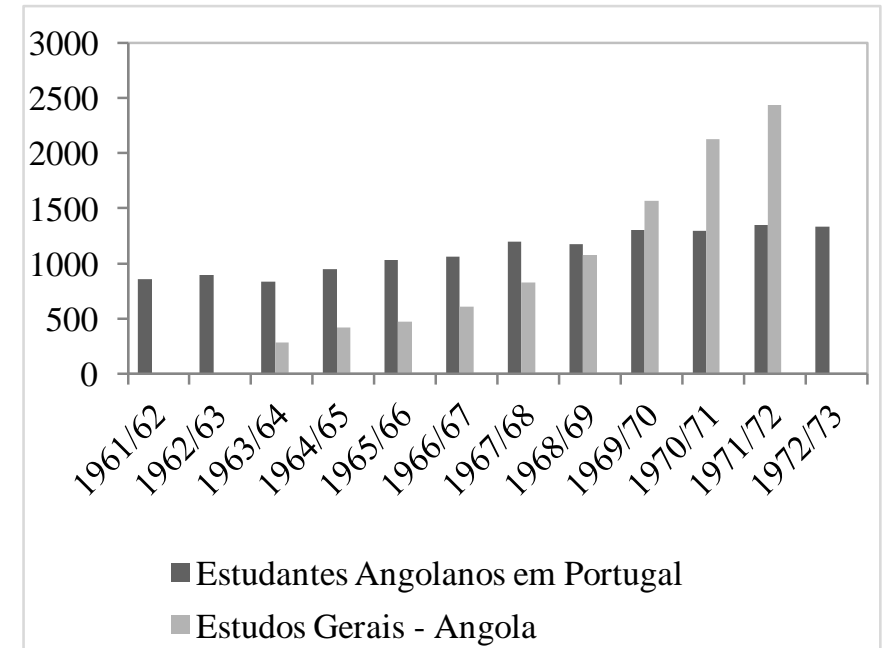

Fonte: baseado em Anuário Estatístico do Ultramar e Anuário Estatístico da Província de Angola Elaboração da autora

No ano letivo de 1963/64, apenas 286 alunos encontravam-se matriculados no ensino superior naquela instituição, no entanto, para a metrópole tinham partido cerca de 839 estudantes. Nos anos letivos seguintes (1964/65 até 1968/69) o número de alunos matriculados nos Estudos Gerais foi aumentando, embora em número pouco significativo, talvez devido ao fato de terem aumentado igualmente os anos dos cursos $\left(2^{\circ}\right.$ ano em diante), continuando a saída de estudantes para a metrópole a registar valores superiores aos dos que permanecem naquele território ultramarino. $\mathrm{O}$ fato dos Estudos Gerais estarem integrados na Universidade Portuguesa, de disponibilizarem pouca oferta formativa e de não concederem o grau de licenciatura, não despertou muito o interesse 
daqueles que continuavam a optar pela formação superior na metrópole. Essa situação altera-se a partir de 1969/70 quando o número de alunos a frequentarem os Estudos Gerais regista valores superiores ao dos que partem. Essa inversão deve-se ao fato dos Estudos Gerais terem adquirido o estatuto de Universidade, passando a designar-se Universidade de Luanda ${ }^{1}$, o que representou uma situação de autonomia em relação às universidades da metrópole, situação reforçada pela autorização que lhes é concedida para atribuírem o grau de licenciado.

\section{O período pós-independência: a política de bolsas de estudo}

A formação de quadros foi um dos desafios mais importantes que o governo da República Popular de Angola (RPA) traçou, concretizando um dos objetivos anunciados durante a luta de libertação. No entanto, o êxodo massivo da maioria dos quadros técnicos de Angola, bem como a necessidade de reestruturação da referida instituição, que levou à mudança de designação para Universidade de Angola $^{2}$, dificultaram essa realização.

Até 1991, a política do Estado angolano em relação ao ensino superior alternou entre a formação superior dentro do país e o envio de bolseiros para o exterior. Neste período (1975 - 1991), “foram formados no interior de Angola 2.174 técnicos superiores e de 1982 a 1992 foram formados um total de 1.733 técnicos superiores em vários países da Europa (ocidental e oriental), da América Latina e da América do Sul" (ZAU, 2002, p. 137). O reacendimento da guerra civil em 1992 forçosamente levou a uma continuidade e até intensificação dessa política de envio.

Quadro 2. Investimento do governo angolano na formação superior (em milhares de dólares)

\begin{tabular}{|l|l|l|l|l|l|}
\hline & $\mathbf{1 9 9 7}$ & $\mathbf{1 9 9 8}$ & $\mathbf{1 9 9 9}$ & $\mathbf{2 0 0 0}$ & $\mathbf{2 0 0 1}$ \\
\hline Universidade & 13.418 & 12.913 & 13.767 & 23.3000 & 31.702 \\
\hline Bolsas & 29.138 & 13.204 & 46.141 & 30.205 & 28.091 \\
\hline
\end{tabular}

Figura 2. Investimento do governo angolano na formação superior (em milhares de dólares)

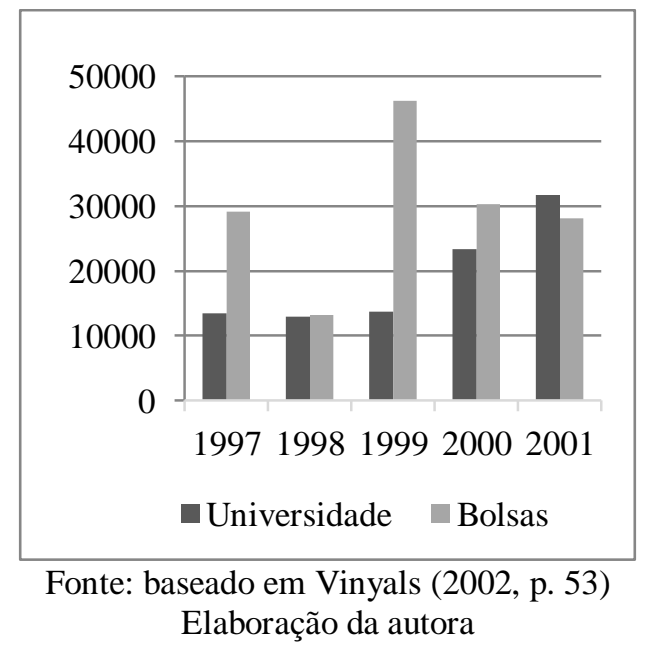

O peso das despesas em bolsas de estudo no Orçamento Geral do Estado (OGE), era superior ao investimento no ensino superior dentro do país. O ano de $1998^{3}$ regista uma diminuição muito acentuada da despesa com as bolsas de estudo, tendo passado de 29.138 milhões de dólares em 1997 para 13.204 milhões de dólares em 1998. Essa descida deveu-se a uma interrupção dos pagamentos das bolsas tendo esta situação sido corrigida no ano seguinte. No ano de 1999 regista-se um acréscimo elevado (46.141 milhões de dólares), justificado pela "liquidação das dívidas relacionadas com o atraso no pagamento das bolsas" (VINYALS, 2002, p. 56). A partir do ano 2000 volta a registar-se uma diminuição nas despesas com bolsas de estudo no exterior. Em relação às despesas com o ensino superior, estas registam uma estagnação entre os anos de 1997-1999, aumentando a partir do ano $2000 .^{4}$ 
Esta desproporção de valores de investimento em educação, a favor da concessão das bolsas de estudo no exterior, não encontra paralelo em qualquer outro país africano (PNUD-Angola, 2002, p. 80). Tomando como comparação os países da Comunidade para o Desenvolvimento da África
Austral (SADC) $)^{5}$, verificamos que no período de 1997-2002, Angola apresentou o menor índice de investimento em educação com uma média de despesa de 4,7 por cento sendo que nos outros países, a média foi de 16,7 por cento (MICS, 2003, p. 126).

Figura 3. Despesas públicas com o setor da educação

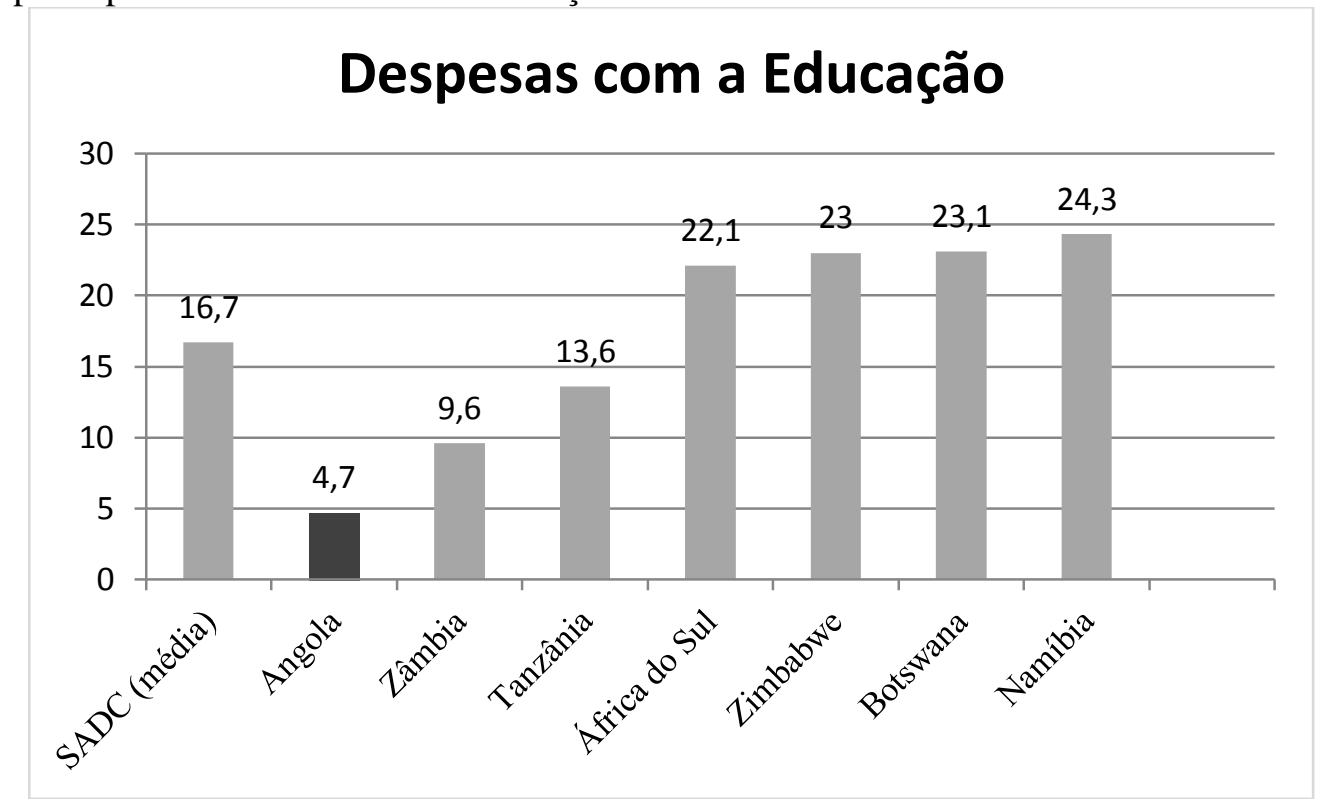

Fonte: baseado em MICS (2003, p.126) e Vinyals (2002, p. 33)

Terminada a guerra, as despesas direcionadas para a defesa deixam de ser prioritárias, assumindo outros setores esse protagonismo. Desde então, tem-se verificado um "crescimento do investimento do Estado nas áreas sociais, materializado no aumento verificado nos últimos dois anos nas dotações orçamentais para a saúde, educação e intervenção comunitária" (LOPES, 2011, p. 47). De acordo com dados do Ministério das Finanças de Angola ${ }^{6}$, a evolução da proporção das despesas com o setor social (na qual se inclui a educação) entre 2007 e 2010 foi a seguinte:

Quadro 3. Proporção das despesas do Estado angolano com o setor social (2007-2010)

\begin{tabular}{|c|c|}
\hline Ano & Despesa Setor Social \\
\hline 2007 & $30,6 \%$ \\
\hline 2008 & $28,8 \%$ \\
\hline 2009 & $31,6 \%$ \\
\hline 2010 & $30,5 \%$ \\
\hline
\end{tabular}

Fonte: Minfin (2011)

Em relação às bolsas de estudo externas, verifica-se a sua continuidade, embora em parâmetros diferentes. Isto é, são enviados estudantes para o estrangeiro somente para áreas de estudo não disponíveis em Angola, ou como complemento da formação já obtida (pós-graduação, mestrado, doutoramento). Em 2008, o INABE apoiava 1.316 bolseiros no exterior, número que aumentou para $2000 \mathrm{em} 2009^{7}$. Esse aumento deve- se ao "incremento das bolsas de estudo oferecidas pelos países com os quais Angola tem acordos de cooperação no domínio do ensino superior e para formação de quadros bem como para a implementação de programas específicos"8. Daí que a ordenação por importância dos países para onde são enviados os estudantes seja a seguinte (ordenação referente ao ano de 2010): 
Quadro 4. Países para onde são enviados os estudantes bolseiros do Estado Angolano e sua ordem de importância

\begin{tabular}{|c|c|}
\hline Ordem & Países \\
\hline $1^{\mathbf{o}}$ & Rússia \\
\hline $2^{\mathbf{o}}$ & Argélia \\
\hline $3^{\mathbf{o}}$ & Cuba \\
\hline $4^{\mathbf{o}}$ & Portugal \\
\hline $5^{\mathbf{0}}$ & Brasil \\
\hline $6^{\mathbf{o}}$ & Polónia \\
\hline $7^{\mathbf{o}}$ & África do Sul \\
\hline $8^{\mathbf{o}}$ & Espanha \\
\hline $9^{\mathbf{o}}$ & China \\
\hline $10^{\mathbf{o}}$ & Marrocos \\
\hline
\end{tabular}

Fonte: baseado em DR Resolução 29/09 (2009, p. 1743) e INABE (2011)

Elaboração da autora

Cuba e Rússia continuam a ser destinos prioritários para o envio de estudantes bolseiros do Estado angolano. O fim da política de inspiração socialista não diminuiu a influência destes países em Angola. Em relação à Argélia, que ocupa o terceiro lugar desta lista, a presença de bolseiros angolanos nas suas instituições de ensino superior demonstra a continuidade do relacionamento de amizade entre os dois países, iniciado em meados do século XX, quando acolheu os protagonistas da luta anticolonial, tendo formado muitos quadros do MPLA ${ }^{9}$. Portugal ocupa o quarto lugar, seguindo-se o Brasil. A Polónia e Marrocos também continuam a receber bolseiros angolanos, dando continuidade a uma cooperação que foi muito intensa no período da política socialista pois receberam muitos bolseiros angolanos nas suas universidades. A recente importância que a China tem ocupado nas relações económicas com Angola colocam este país na nona posição de receção de estudantes bolseiros angolanos.
Em relação à África do Sul, esta ocupa a sétima posição. Como potência regional e membro da SADC, esperar-se-ia que este país assumisse um protagonismo maior na cooperação com Angola, nomeadamente, na cooperação educativa. As alterações políticas registadas na África do Sul com o fim do apartheid permitiram a reaproximação dos dois países, possibilitando a intensificação do fluxo migratório de estudantes angolanos para aquele país. Muitos estudantes optaram por este destino devido à sua proximidade geográfica, o que minimiza os custos económicos bem como pela hipótese de aprendizagem da língua inglesa, entendida como uma mais-valia na formação, e na posterior integração no mercado de trabalho.

De acordo com dados fornecidos pelo INABE em Janeiro de 2011, encontravam-se nessa data 1.974 bolseiros angolanos no exterior, com bolsas de estudo daquela instituição, distribuídos por 35 países, dos quais destacamos aqueles onde se encontram o maior número de bolseiros:

Quadro 5. Número de bolseiros do INABE no exterior em 2010

\begin{tabular}{|c|c|c|c|c|}
\hline País & Licenciaturas & Mestrado & Doutoramento & Total \\
\hline África do Sul & 29 & 5 & 3 & 37 \\
\hline Alemanha & 2 & - & - & 2 \\
\hline Argélia & 245 & - & - & 245 \\
\hline Austrália & 1 & - & - & 2 \\
\hline Bélgica & 2 & - & 7 & 153 \\
\hline Brasil & 141 & 5 & - & 16 \\
\hline Burkina Faso & 13 & 3 & - & 4 \\
\hline Rep. Checa & 4 & - & 1 & 47 \\
\hline China & 44 & 2 & 124 & 728 \\
\hline Congo & - & - & 2 & 13 \\
\hline Cuba & 574 & 13 & & \\
\hline E.U.A. & 8 & 3 & & 1 \\
\hline
\end{tabular}




\begin{tabular}{|c|c|c|c|c|}
\hline Eslováquia & 2 & - & - & 2 \\
\hline Espanha & 3 & 2 & 9 & 14 \\
\hline França & - & - & 4 & 4 \\
\hline Ghana & 2 & - & - & 2 \\
\hline Grécia & 1 & - & - & 1 \\
\hline Holanda & 1 & - & - & 1 \\
\hline Inglaterra & 5 & - & - & 5 \\
\hline Marrocos & 53 & - & - & 53 \\
\hline Moçambique & 1 & 3 & - & 4 \\
\hline Namíbia & 2 & - & - & 2 \\
\hline Noruega & - & - & 1 & 1 \\
\hline Polónia & 68 & - & - & 68 \\
\hline Portugal & 71 & 26 & 51 & 148 \\
\hline R. D. Congo & 4 & 4 & 3 & 11 \\
\hline Roménia & 46 & - & 1 & 47 \\
\hline Rússia & 303 & - & 9 & 312 \\
\hline Sérvia & 3 & - & - & 3 \\
\hline Suíça & 1 & - & - & 1 \\
\hline Togo & 5 & - & - & 5 \\
\hline Tunísia & 10 & - & - & 10 \\
\hline Ucrânia & 22 & - & - & 22 \\
\hline Vietname & - & - & 2 & 2 \\
\hline Zimbabué & 4 & 3 & - & 7 \\
\hline Total & 1670 & 69 & 218 & 1974 \\
\hline
\end{tabular}

Fonte: INABE (2011)

Cuba aparece assim como o país que acolhe atualmente o maior número de bolseiros angolanos, com 728 estudantes. Segue-se a Rússia com 312 bolseiros. Segundo um responsável do INABE, o relacionamento com Cuba intensificou-se nos últimos anos, sobretudo em áreas sociais como a saúde e a educação:

Depois daquele período em que os cubanos tiveram que sair de Angola tivemos muita dificuldade em substituí-los nas áreas sociais, sobretudo os médicos. Mas agora estão a regressar outra vez. Tivemos que pedir para eles virem outra vez porque continuamos a não conseguir pessoas formadas suficientes para trabalhar. Sobretudo no interior do país. Os portugueses e os brasileiros só aceitam viver na cidade, com bom ordenado, casa e carro pago. Os cubanos não, vêm para cá e não recebem quase nada porque estão aqui em missão de Estado, a servir o país deles e nós precisamos disso. Angola não é só Luanda. Temos que tratar também das províncias (responsável INABE).

Segundo o mesmo responsável do INABE, fica menos dispendioso para o Estado angolano enviar os seus bolseiros para Cuba, para além que está mais assegurado o seu regresso ao país depois de concluída a formação:

Em Portugal ou noutro país da Europa um estudante de licenciatura tem uma bolsa mensal de 750 dólares. Para quem faz mestrado ou doutoramento a bolsa é de 1500 dólares. Em Cuba o estudante de licenciatura tem bolsa de 500 dólares e os de mestrado e doutoramento 1250. E os que vão para Cuba regressam todos. Os que vão para Portugal não, a maioria fica lá (responsável INABE).

Brasil e Portugal aparecem na quarta (153 bolseiros) e quinta (148 bolseiros) posição respetivamente, como países de acolhimento dos bolseiros angolanos.

De salientar que estes dados refletem apenas o número de bolseiros do INABE e não o número total de estudantes angolanos no exterior, nomeadamente os bolseiros de empresas, de outras instituições (religiosas e não governamentais) e aqueles que partem com o apoio das famílias. Quanto a estes últimos, a escolha do destino obedece a uma série de critérios. Em primeiro lugar, ter família ou amigos neste país apresenta-se como um critério fundamental (apoio no período inicial de integração), seguindo-se a situação económica das 
famílias pois, na maioria dos casos, estas têm que elaborar estratégias (aluguer da casa, bem como pequenos negócios que complementam o orçamento familiar) para financiar a formação dos seus descendentes no exterior.
Em 2009, o número de estudantes universitários que se encontravam no exterior sem bolsa do INABE era superior ao número de bolseiros daquela instituição.

Quadro 6. Distribuição dos estudantes angolanos no exterior (não bolseiros do INABE) - 2009

\begin{tabular}{|l|c|c|c|}
\hline País & Graduação & Pós-Graduação & Total \\
\hline África do Sul & 15 & 60 & 75 \\
\hline Argélia & 10 & - & 10 \\
\hline Brasil & 70 & 15 & 85 \\
\hline Canadá & 5 & 3 & 15 \\
\hline China & 10 & 5 & 50 \\
\hline Congo Brazzaville & 50 & - & 6 \\
\hline Coreia do Sul & 5 & 1 & 70 \\
\hline Cuba & 50 & 20 & 12 \\
\hline Eslováquia & 7 & 5 & 17 \\
\hline França & 10 & 7 & 25 \\
\hline Inglaterra & 15 & 10 & 25 \\
\hline Itália & 10 & 15 & 72 \\
\hline Marrocos & 72 & - & 1000 \\
\hline Namíbia & 1000 & - & 25 \\
\hline Polónia & 20 & 5 & 255 \\
\hline Portugal & 205 & 50 & 30 \\
\hline República Checa & 25 & 5 & 80 \\
\hline RDC & 80 & - & 100 \\
\hline Rússia & 80 & 20 & 73 \\
\hline Ucrânia & 50 & 23 & 60 \\
\hline Zâmbia & 60 & - & 30 \\
\hline Zimbabwe & 30 & - & $\mathbf{2 1 2 3}$ \\
\hline Total & $\mathbf{1 8 7 9}$ & $\mathbf{2 4 4}$ & \\
\hline
\end{tabular}

Fonte: Resolução 29/09 (2009, p. 1744)

Quando a escolha para partir para o estrangeiro para realização da formação superior não parte do Estado mas sim das famílias, Portugal aparece na segunda posição com 225 estudantes, antecedido apenas pela Namíbia com 1.000 estudantes. De destacar aqui o papel da Namíbia que, embora não conste da lista de países prioritários para envio dos bolseiros do Estado angolano, é o país que mais recebe estudantes angolanos sem bolsa. A sua proximidade geográfica de Angola é certamente um dos fatores de decisão. De salientar igualmente que, para além da África do Sul, nenhum dos outros países que constituem a SADC se encontra na lista de países prioritários, nem da lista de destino dos estudantes não bolseiros, o que demonstra uma preocupante falta de cooperação entre os Estados membros dessa comunidade, no que diz respeito à formação superior.

\section{As relações de cooperação entre Portugal - Angola - Brasil}

A escolha de Portugal para a realização da formação superior, acaba por ser, ainda nos dias de hoje, o resultado de séculos de interação entre Portugal e Angola, ou seja, a deslocação de estudantes angolanos para Portugal não é apenas um processo de migração temporária. A existência de uma significativa comunidade imigrante angolana em Portugal, constituída ao longo dos anos, a possibilidade de aquisição da nacionalidade portuguesa, bem como a proximidade entre os currículos escolares são fatores que têm influenciado essa escolha. Por outro lado, a realização da formação superior em Portugal pelos ascendentes (pais e mesmo avós) tem um efeito reprodutivo, ou seja, está na origem do envio de filhos e netos também para Portugal, no intuito de 
verem, através destas novas gerações, reproduzido o mesmo percurso escolar.

Nos últimos anos (particularmente a partir de 2003), o Brasil vem assumindo um papel preponderante nas dinâmicas de cooperação escolar com Angola. Neste contexto, a escolha do Brasil como país de destino, para realização da formação superior, não representa apenas "um movimento de simples deslocamento de indivíduos entre um país de origem e um país de acolhimento. Trata-se de um contexto em que os indivíduos que migram dentro desse processo de migração especial cumprem metas postas por seus países em termos do próprio desenvolvimento" (GUSMÃO, 2009, p. 16). Além da partilha de um passado comum (colonização portuguesa), o Brasil como país emergente aparece como "concorrente" de Portugal, demonstrando sobretudo a intenção de fortalecer a sua ligação ao continente africano, numa tentativa de se reconciliar com o passado, mas também de reconhecimento do papel fundamental da sua ligação a estes países, não só dentro do quadro da CPLP, mas também da cooperação sul-sul.

$\mathrm{O}$ relacionamento entre os três países remonta ao século $X V$. Portugal chegou à foz do rio Zaire (Angola) em 1482 e, a terras de Vera Cruz (Brasil), em 1500. Relações comerciais (económicas e expansionistas) estiveram na origem do relacionamento entre os três territórios. A colonização do Brasil, inserida no que se convencionou designar de "Segundo Império Colonial", e a de Angola descrita como se inserindo no "Terceiro Império Colonial" (ALEXANDRE, 2000) levou à partilha de uma herança histórica e linguística idêntica, bem como de identidades culturais, étnicas e religiosas, (infelizmente) consolidadas pelo tráfico de escravos entre os três países. De fato, a região que hoje corresponde ao território angolano foi aquela que mais escravos forneceu para o Brasil. Estima-se que entre o "século XVI e XIX cerca de três milhões de angolanos terão sido enviados para o Brasil" (FERREIRA, 2004, p. 86), estabelecendo desde logo relações culturais e comerciais bem como uma ligação que atualmente se apresenta determinante no processo de cooperação entre os três países.

$\mathrm{O}$ enquadramento institucional da cooperação portuguesa com Angola começou imediatamente após a independência (MONTEIRO, 2001, p. 157), tendo o Acordo Geral de Cooperação sido ratificado em $1979^{10}$ com a publicação da Lei 6/79 de 9 de fevereiro. Este documento legislativo, posteriormente atualizado ao longo dos anos, marca institucionalmente $\mathrm{o}$ início do processo de cooperação entre Portugal e a sua antiga colónia, então denominada, República Popular de Angola (hoje apenas República de Angola). Em relação ao Brasil, as relações entre Brasil e Angola estabeleceram-se logo em 1975 "em virtude do Brasil ter sido o primeiro país a reconhecer não somente a independência da antiga colónia portuguesa, mas também o seu governo, liderado pelo MPLA" (ApexBrasil, 2010, p. 13).

No que toca à política educativa,

A dinâmica da constituição dos novos Estados nacionais africanos, principalmente os de língua oficial portuguesa (PALOP), tem conduzido um número significativo de jovens africanos a buscar, no Brasil e em Portugal, possibilidades de formação e qualificação de nível técnico, médio e superior (GUSMẪO, 2009, p.17).

No intuito de aprofundar as relações entre os países que falam português foi criada, em 1996, a Comunidade dos Países de Língua Portuguesa $(\mathrm{CPLP})^{11}$, que, constitui um dos quadros institucionais de cooperação entre estes países. Como comunidade lusófona que liga os quatro continentes, a CPLP pretende aumentar os fluxos da cooperação entre os estados que a compõem bem como privilegiar o espaço cultural e social que os liga, dando origem a um "espaço cultural transnacional e multicontinental” (MARCHUETA, 2003, p. 61).

Angola tem sido o Estado membro da CPLP que mais atenção tem despertado a Portugal e ao Brasil devido ao seu potencial económico e estratégico (MARCHUETA, 2003). Por seu lado, Angola vê Portugal como uma porta de acesso a uma das regiões mais ricas e avançadas do mundo a União Europeia (U.E) - bem como um porta-voz junto da comunidade dadora internacional (MARCHUETA, 2003, p. 95), posição partilhada pelo Brasil e pelos restantes países membros da CPLP.

Em relação à educação, em 1998, no âmbito da CPLP, estenderam-se os acordos de cooperação à educação, com a celebração do Acordo de Cooperação entre Instituições de Ensino Superior dos Países Membros da CPLP, no qual ficou definido que "os estados-membros promoverão a cooperação entre instituições de ensino superior mediante atividades de apoio à educação e cultura, à pesquisa e ao desenvolvimento científico e tecnológico" "12. Na sequência desse acordo, Portugal tem disponibilizado acesso à formação superior a estudantes dos países que integram a CPLP. Quanto aos estudantes angolanos, o seu número tem vindo a aumentar na última década. 
Quadro 7. Alunos Nacionais de Angola Inscritos nas Universidades Portuguesas por área de Educação e Formação (CNAEF), 1997-1998 a 2007-2008

\begin{tabular}{|c|c|c|c|c|c|c|c|c|c|c|c|}
\hline $\begin{array}{l}\text { Áreas de Educação } \\
\text { e Formação }\end{array}$ & $\begin{array}{l}1997 / \\
98\end{array}$ & $\begin{array}{l}1998 / \\
99\end{array}$ & $\begin{array}{l}1999 / \\
00\end{array}$ & $\begin{array}{l}2000 / \\
01\end{array}$ & $\begin{array}{l}2001 / \\
02\end{array}$ & $\begin{array}{l}2002 / \\
03\end{array}$ & $\begin{array}{l}2003 / \\
04\end{array}$ & $\begin{array}{l}2004 / \\
05\end{array}$ & $\begin{array}{l}2005 / \\
06\end{array}$ & $\begin{array}{l}2006 / \\
07\end{array}$ & $\begin{array}{l}2007 / \\
08\end{array}$ \\
\hline Educação & 174 & 103 & 136 & 328 & 178 & 166 & 96 & 82 & 174 & 118 & 79 \\
\hline $\begin{array}{l}\text { Artes e } \\
\text { Humanidades }\end{array}$ & 111 & 137 & 157 & 111 & 144 & 155 & 178 & 277 & 263 & 308 & 284 \\
\hline $\begin{array}{l}\text { Ciências Sociais, } \\
\text { Comércio e Direito }\end{array}$ & 875 & 994 & 1117 & 1257 & 1708 & 1796 & 2012 & 2622 & 2563 & 3174 & 3113 \\
\hline $\begin{array}{l}\text { Ciências, } \\
\text { Matemática e } \\
\text { Informática }\end{array}$ & 125 & 145 & 102 & 155 & 171 & 220 & 258 & 397 & 250 & 305 & 315 \\
\hline $\begin{array}{l}\text { Engenharia, } \\
\text { Indústrias } \\
\text { Transformadoras e } \\
\text { Construção }\end{array}$ & 347 & 362 & 373 & 456 & 457 & 523 & 555 & 514 & 467 & 479 & 487 \\
\hline Agricultura & 104 & 47 & 48 & 40 & 76 & 60 & 53 & 47 & 21 & 18 & 35 \\
\hline $\begin{array}{l}\text { Saúde e Proteção } \\
\text { Social }\end{array}$ & 148 & 174 & 185 & 216 & 279 & 271 & 245 & 308 & 289 & 293 & 200 \\
\hline Serviços & 144 & 149 & 140 & 148 & 170 & 176 & 130 & 111 & 89 & 99 & 135 \\
\hline Total & 2028 & 2111 & 2258 & 2711 & 3183 & 3367 & 3527 & 4258 & 4116 & 4794 & 4648 \\
\hline
\end{tabular}

Fonte: "Relatório Ciência, Tecnologia e Ensino Superior: Cooperação Entre Portugal e a CPLP" Disponível no endereço http://www.gpeari.mctes.pt (acedido a 10/02/2011).

O número de estudantes angolanos em instituições de ensino superior portuguesas conheceu assim um crescimento significativo com um aumento na ordem dos 43 por cento entre 1997/98, (2028 alunos) e 2007/08 (4648 alunos).

Destacam-se as áreas das Ciências Sociais, Comércio e Direito com 3.113 alunos inscritos no ano letivo de 2007/08 um aumento significativo se tomarmos em consideração os 875 registados no ano letivo 1997/98, seguido da área de Engenharia, Indústrias Transformadoras e Construção com 487 alunos. Em contrapartida, a área da Educação (Ciências da Educação) e Agricultura são as áreas que registam menos inscritos, com 79 e 35 respetivamente. $\mathrm{O}$ pouco interesse registado na área da Agricultura poderá estar ligado ao atraso que este setor ainda regista em Angola, apresentando-se pouco atrativo, condicionando a entrada imediata no mercado de trabalho. Em relação à área da Educação, tratando-se de um setor em franca expansão, estando com maior oferta ${ }^{13}$ em Angola, regista, contudo, menor procura enquanto área específica, dado o diploma obtido nas outras áreas científicas também dar possibilidade de lecionação nos diferentes níveis de ensino.

No entanto, apesar destas intenções, a cooperação entre os membros da CPLP ainda se apresenta incipiente para as reais necessidades de Angola. Na realidade, assiste-se a uma multiplicidade de acordos e planos de intenções que não se traduzem em resultados práticos. Palma e Pessoa constatam que as ações de cooperação promovidas entre instituições de ensino superior português e as dos países da CPLP, apresentam-se dispersas, anárquicas e inorgânicas, sendo abundantes em manifestações de intenções, acordos, protocolos ou convénios que depois não são postos em execução (PALMA \& PESSOA, 2004, p. 102).

Se outrora o comércio triangular viabilizou o empreendimento colonial português e ligou os três continentes, atualmente essa ligação é mantida pelos acordos de cooperação estabelecidos, de forma independente, entre os países. Assim, de Angola partem com destino a Portugal estudantes bolseiros com o objetivo de adquirirem formação superior, retornando posteriormente, já formados, para desempenharem as suas funções em Angola. De Portugal para Angola regressam não só os angolanos já formados, como também são enviados professores e técnicos para ajudarem a melhorar a oferta de formação superior em Angola. De Angola para o Brasil partem igualmente bolseiros com o mesmo objetivo. Do Brasil para Angola regressam estudantes já formados. Entre Portugal e o Brasil estabelece-se um intercâmbio internacional ao nível de pós-graduações (mestrado, doutoramento, pósdoutoramento), bem como o aperfeiçoamento de docentes e pesquisadores. 


\section{Conclusão}

Os diversos constrangimentos que Angola tem enfrentado levaram a uma necessidade de envio dos seus estudantes universitários para o exterior, de modo a formar os recursos humanos que o país necessita. Mediante acordos de cooperação com diversos países, têm sido enviados para o exterior, ao longo dos anos, estudantes angolanos de modo a darem continuidade à sua formação. Se no passado esse envio passava quase em exclusivo por Portugal (metrópole), no período pós-independência Cuba e Rússia assumem essa posição, surgindo como os países que receberam mais estudantes angolanos durante o período de construção do estado socialista. Com o fim dessa política e a adoção do liberalismo económico, novos países surgem como parceiros de cooperação, não inibindo, no entanto, a posição privilegiada de Cuba e da Rússia.

Portugal e Brasil, dois países com fortes ligações históricas a Angola, foram igualmente, ao longo dos anos, parceiros de cooperação no que toca à formação superior de angolanos, ao receberem muitos estudantes angolanos nas suas instituições de ensino superior. Portugal assumiu a sua posição de parceiro de cooperação de Angola desde a independência deste país, recebendo muitos estudantes angolanos nas suas instituições de ensino superior, sobretudo no período de reinício da guerra civil (1992-2002). Mais recentemente, o Brasil, reconhecendo a importância do continente africano para a sua política de cooperação, "elegeu" Angola como um dos seus principais parceiros no continente, disponibilizando igualmente muitas vagas nas suas instituições de ensino superior para estudantes angolanos, ofuscando assim o protagonismo de Portugal. Entre estes três países vem-se estabelecendo assim uma rede de cooperação estudantil em que Angola tem sido a principal beneficiada, reforçada com a criação da CPLP. Resta, contudo, saber se Angola tem aproveitado esse apoio da melhor forma, ao reconhecer o papel destes países, mas, sobretudo, ao aproveitar os recursos humanos qualificados regressados destes países no seu processo de desenvolvimento.

\section{Notas}

1 Decreto-lei 48790 de 23 de Dezembro de 1968.

2 Portaria 77-A/76.

3 Reinício da guerra civil.

4 "A proporção da despesa total com o setor da educação diminuiu de 6,1 por cento em 1998 para 3,0 por cento em 1999, recuperando depois em 2000 (4,3 por cento) e em 2001 (6,4 por cento)" (PNUD-Angola, 2002: 80).

5 Southern Africa Development Community Comunidade para o desenvolvimento da África Austral: organização sub-regional de integração económica dos países da África Austral. Fazem parte os seguintes países: Angola, África do Sul, Botswana, Ilhas Maurícias, Lesotho, Malawi, Moçambique, Namíbia, República Democrática do Congo, Seychelles, Swazilândia, Tanzânia, Zâmbia, Zimbabué.

6 http://www.minfin.gov.ao (acedido a 23/12/2011).

7 DR Resolução no 29/09 de 15 de Abril, do Conselho de Ministros.

8 DR Resolução no 29/09 de 15 de Abril de 2009, pp. 1744.

9 Pepetela, Edmundo Rocha, entre muitos outros.

10 O período compreendido entre 1975-1980 ficou marcado por uma profunda instabilidade em Angola (independência, êxodo massivo dos recursos humanos qualificados, paralisação económica, tentativa de golpe de Estado dentro do mesmo partido, morte do presidente Agostinho Neto) condicionando a celebração de qualquer tipo de acordo de cooperação.

11 Fazem parte da CPLP os seguintes países: Angola, Brasil, Cabo Verde, Guiné Bissau, Moçambique, Portugal, São Tomé e Príncipe e Timor Leste.

$12 \mathrm{http}: / /$ www.cplp.org (acedido a 24/12/2011).

13 A falta de professores no período pósindependência levou à criação de Escolas de Formação de Professores, posteriormente designadas de Instituto Superior de Ciências da Educação (ISCED), em várias províncias de Angola, nomeadamente em Luanda, Lubango, Benguela, Huambo, Cabinda e Uíge. Atualmente, as novas regiões académicas também lecionam cursos de formação de professores, aumentando a oferta formativa.

\section{Referências}

AFONSO, M. M. Cooperação para o desenvolvimento: evolução e perspetivas futuras. Lisboa: CIDAC, 1995.

ALEXANDRE, V. Velho Brasil novas áfricas: Portugal e o Império (1808 - 1975). Porto: Edições Afrontamento, 2000. 
Anuário Estatístico do Ultramar (1961 - 1973). Lisboa: INE.

Anuário Estatístico da Província de Angola (1963 1972). Luanda: INE Angola.

ApexBrasil (Agência Brasileira de Promoção de Exportações e Investimentos). Angola: estudo de oportunidades. Brasília, Unidade de Inteligência Comercial e Competitiva. Disponível em: http://www.pexbrasil.com.br. Acesso em: 24/12/2011, 2010.

CARVALHO, C. O centro de estudos africanos e a cooperação em educação. In Livro de Atas do I COOPEDU. Lisboa: CEA, 41-46, 2010.

CPLP, Acordo de cooperação entre instituições de ensino superior dos países membros da CPLP. Disponível em: http://www.cplp.org. Acesso em: 24/12/2011.

Diário da República (Angola), quarta-feira, 15 de Abril de 2009, I ${ }^{a}$ Série, No 69 - Resolução no 29/09 do conselho de ministros relativo ao programa executivo do setor do ensino superior para o ano de 2009.

FERNANDES, T., MARTINS, J., RODRIGUES, L. Cooperar para o desenvolvimento: memória $e$ estudos. Oeiras: Cadernos do INA, 24, 2005.

FERREIRA, R. A força de um passado comum: relações Brasil-PALOP. Lisboa: Janus/ Público/UAL, 86-87, 2004.

GPEARI/MCTES. Relatório ciência, tecnologia e ensino superior: cooperação entre Portugal e a CPLP, 2009. Disponível em: http://www.gpeari.mctes.pt. Acesso em: 10/10/2011.

GUSMÃO, N. Introdução. Campinas, Proposições, 20 (1) (58): 13-21, 2009.

INABE. Informações sobre bolsas de estudo. Luanda: Instituto Nacional de Bolsas de Estudo, 2011.
INSTITUTO PORTUGUÊS DE APOIO AO DESENVOLVIMENTO (IPAD). PIC: Programa indicativo de cooperação Portugal Angola (20072010). Lisboa: IPAD. Disponível em: http://www.ipad.pt.Acesso em: (Acedido a 12/06/12).

LARA, L. Documentos e comentários para a história do MPLA (até Fevereiro de 1961), Lisboa: Publicações Dom Quixote, 1999.

LOPES, C. Candongueiros \& kupapatas: acumulação, risco e sobrevivência na economia informal em Angola. Lisboa: Principia, 2011.

MARCHUETA, M. R. A CPLP e seu enquadramento. Lisboa: Instituto Diplomático Ministério dos Negócios Estrangeiros, 2003.

MICS. Inquérito de indicadores múltiplos. Luanda: INE \& UNICEF, 2003.

MINISTÉRIO DAS FINANÇAS DE ANGOLA (MINFIN). Disponível em: http://www.minfin.gov.ao. Acesso em 23/12/2011.

MONTEIRO, R. L. A África na política de cooperação europeia. Lisboa: ISCSP, 2001.

PALMA, E. e PESSOA, I. Cooperação universitária (I). Lisboa: Janus/Público/UAL: 102-103, 2004.

PNUD - Angola. Os desafios pós-guerra. Luanda: Nações Unidas, 2002.

PNUD. Declaração do Milénio, 2000. Disponível em: http://www.un.org. Acesso em: 1/12/2011.

PNUD. Relatório do desenvolvimento humano, 2005.

VINYALS, L. O Financiamento público dos sociais em Angola. Cascais: Principia, 2002.

ZAU, F. Trilhos para o desenvolvimento. Lisboa: Universidade Aberta, 2002.

\section{Sobre a autora}

Ermelinda Liberato é PhD em Estudos Africanos pelo ISCTE-IUL, Lisboa. Investigadora do Centro de Estudos Internacionais do ISCTE-IUL (CEI-IUL). Professora auxiliar da Faculdade de Ciências Sociais da Universidade Agostinho Neto (FCS-UAN), Luanda - Angola.

Recebido em julho de 2016.

Aprovado em novembro de 2016. 